\title{
Electron microscopic investigation of high-temperature oxide superconductors*
}

\author{
G N SUBBANNA \\ Materials Research Laboratory, Indian Institute of Science, Bangalore 560 012, India \\ MS received 25 March 1988
}

\begin{abstract}
Electron microscopic investigations have been carried out on superconducting $\mathrm{YBa}_{2} \mathrm{Cu}_{3} \mathrm{O}_{7-\delta}, \mathrm{NdBa}_{2} \mathrm{Cu}_{3} \mathrm{O}_{7-\delta}$ and related oxides. All these orthorhombic oxides exhibit twin domains. Based on high resolution electron microscopy, it is shown that there is no significant change in the structure across the twins. Oxides of the $\mathrm{La}_{2-x} \mathrm{Sr}_{x}\left(\mathrm{Ba}_{x}\right) \mathrm{CuO}_{4}$ system do not show twins, but exhibit other types of defects. Twins appear to be characteristic of only the orthorhombic 123 structures.
\end{abstract}

Keywords. Electron microscopy; twins; oxide superconductors.

\section{Introduction}

Two series of high temperature oxide superconductors have been intensively investigated in the last few months. These are the 123 oxides of the type $\mathrm{LnBa}_{2} \mathrm{Cu}_{3} \mathrm{O}_{7-\delta},\left(\mathrm{Ln}=\mathrm{Y}\right.$ or rare earth) with $T_{c} 90 \pm 5 \mathrm{~K}$ and $\mathrm{La}_{2-x} \mathrm{Sr}_{x}\left(\mathrm{Ba}_{x}\right) \mathrm{CuO}_{4}$ of the $\mathrm{K}_{2} \mathrm{NiF}_{4}$ structure with $T_{c} \sim 30 \pm 10 \mathrm{~K}$ (Nelson et al 1987; Rao 1987, 1988a, b). All these oxides possess orthorhombic structures in the superconducting phase. In the case of $\mathrm{YBa}_{2} \mathrm{Cu}_{3} \mathrm{O}_{7-\delta}$, the orthorhombic structure extends up to $\delta \sim 0 \cdot 6$. Electron microscopy has been employed to investigate defects as well as twins in $\mathrm{YBa}_{2} \mathrm{Cu}_{3} \mathrm{O}_{7-\delta}$ (Rao 1987; Rao et al 1988; Raveau et al 1987; Subbanna et al 1987). It has been shown that twins in the superconducting $\mathrm{YBa}_{2} \mathrm{Cu}_{3} \mathrm{O}_{7-\delta}$ are related to the orthorhombic structure, which in turn depends on the presence of $\mathrm{Cu}-\mathrm{O}$ chains along the $b$-axis (Rao 1988a). In the present study, detailed electron microscopic investigations have been carried out on several 123 oxides to understand the nature of twins. In addition, oxides of the $\mathrm{La}_{2-x} \mathrm{Sr}_{x}\left(\mathrm{Ba}_{x}\right) \mathrm{CuO}_{4}$ system have been investigated by electron microscopy.

\section{Experimental}

Samples of $\mathrm{YBa}_{2} \mathrm{Cu}_{3} \mathrm{O}_{7-\delta}$ and other 123 oxides as well as $\mathrm{La}_{2-x} \mathrm{Sr}_{x}\left(\mathrm{Ba}_{x}\right) \mathrm{CuO}_{4}$ were prepared by the ceramic route starting with the appropriate mixtures of the component metal oxides or/and carbonates. Repeated grinding and pelletizing were carried out to ensure formation of the desired oxide. For varying the oxygen stoichiometry of $\mathrm{YBa}_{2} \mathrm{Cu}_{3} \mathrm{O}_{7}$, the samples were heat-treated in an appropriate $\left(\mathrm{O}_{2} / \mathrm{N}_{2}\right)$ atmosphere. Samples of $\mathrm{La}_{2-x} \mathrm{Sr}_{x}\left(\mathrm{Ba}_{x}\right) \mathrm{CuO}_{4}$ were prepared at $1200 \mathrm{~K}$ in air.

$\mathrm{X}$-ray powder diffraction patterns were recorded (Philips PW 1140) using $\mathrm{CuK}_{\alpha}$ radiation to establish the structure of the oxides. Resistivity was measured using the four-probe d.c. method. Electron microscopic investigations were carried out in a

\footnotetext{
*Communication No. 100 from Materials Research Laboratory.
} 
JEOL JEM 200CX and Philips EM 301 (for in situ low temperature work) electron microscopes. The samples for the microscopic examination were prepared by dispersing finely ground powders on holey carbon grids.

\section{Results and discussion}

In figure 1a, we show the bright-field image of a sample of superconducting $\mathrm{YBa}_{2} \mathrm{Cu}_{3} \mathrm{O}_{7}\left(T_{c} \sim 90 \mathrm{~K}\right)$ recorded at room temperature, the sample for microscopic examination being prepared (by dispersing the powder in acetone) at room temperature. The image clearly shows twin domains of $\sim 200 \AA$ width. Cooling the sample in the microscope down to $77 \mathrm{~K}$, produced no change in the twin density or in the width of the domain. Polycrystalline $\mathrm{YBa}_{2} \mathrm{Cu}_{3} \mathrm{O}_{7}$ dropped into liquid nitrogen for preparing samples for microscopic examination, however, showed a large number of $90^{\circ}$ twins (figure $1 \mathrm{~b}$ ). The average width of these twin domains was considerably smaller $(\sim 90 \AA)$. The estimated width of the twins, obtained by the simple empirical rule, $S=(a b / a-b)$, where $a$ and $b$ are unit cell parameters of the orthorhombic phase (Pande et al 1987), works out to be $\sim 250 \AA$. Pande et al reported variable twin widths ranging from $150 \AA$ to $4000 \AA$. The small twin domains shown in figure $1 \mathrm{~b}$ do not conform to the simple rule of Pande et al. In spite of the small width and high twin density, the $T_{c}$ of this sample (zero-resistance) of $\mathrm{YBa}_{2} \mathrm{Cu}_{3} \mathrm{O}_{7}$ remained around $92 \mathrm{~K}$.

$\mathrm{YBa}_{2} \mathrm{Cu}_{3} \mathrm{O}_{6 \cdot 7}$, which is also orthorhombic and superconducting with $\left(T_{c} \sim 60 \mathrm{~K}\right)$ (Rao 1988a), shows twins (figure 2a) similar to $\mathrm{YBa}_{2} \mathrm{Cu}_{3} \mathrm{O}_{7}$. Although the $T_{c}$ is lower,
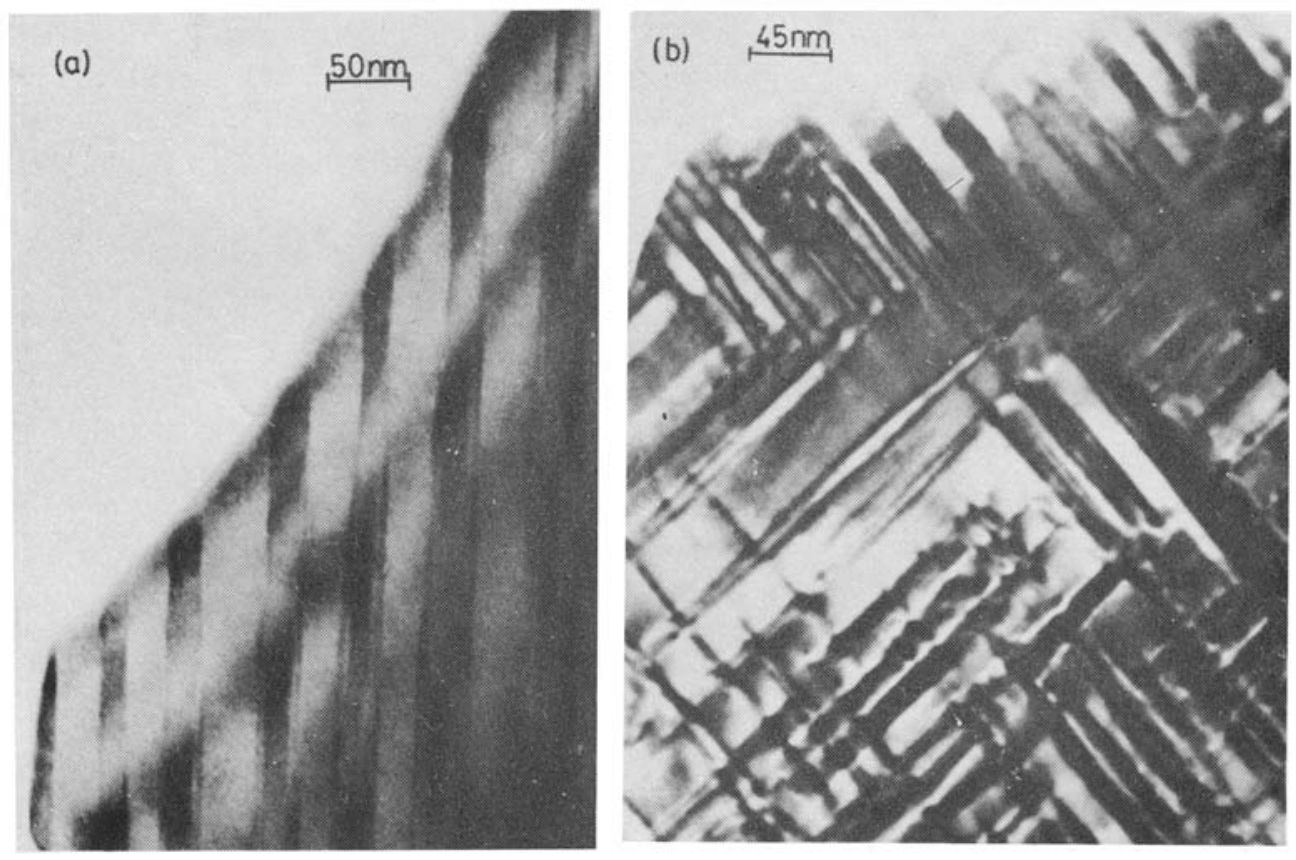

Figure 1. Bright-field images of (a) twins in $\mathrm{YBa}_{2} \mathrm{Cu}_{3} \mathrm{O}_{7}$ and (b) $90^{\prime}$ twins in $\mathrm{YBa}_{2} \mathrm{Cu}_{3} \mathrm{O}$ ( $\mathrm{LN}_{2}$ preparation). 

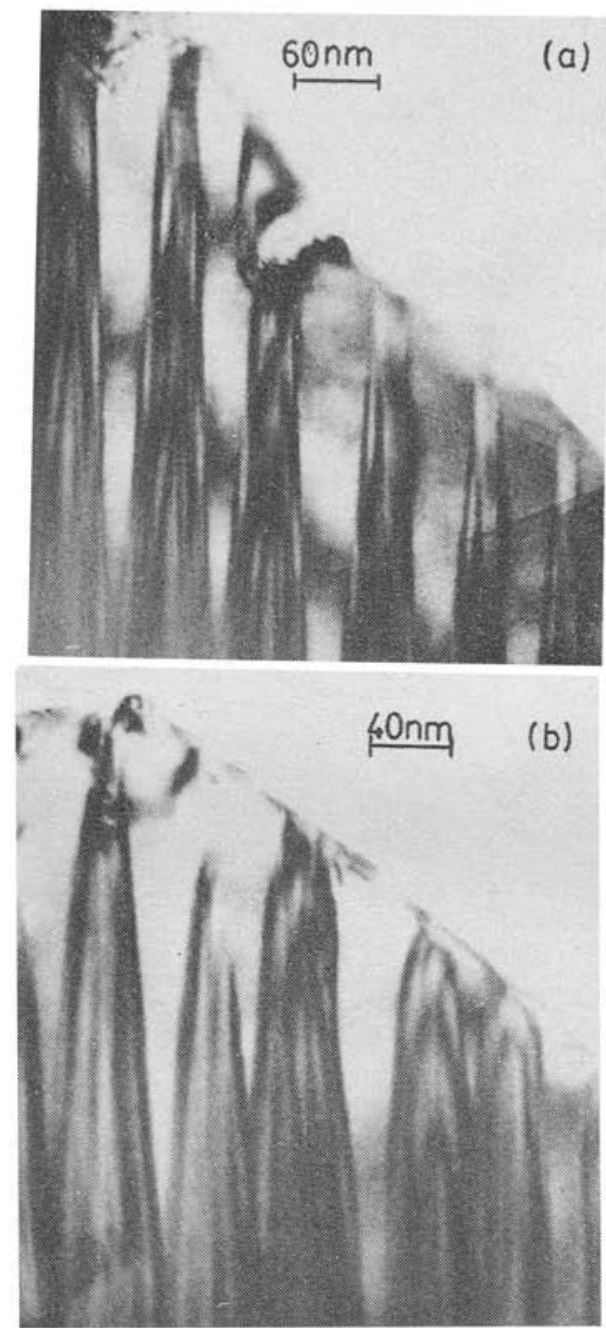

$40 \mathrm{~nm}$

(c)

Figure 2. Bright-field images of (a) twins in $\mathrm{YBa}_{2} \mathrm{Cu}_{3} \mathrm{O}_{6-7}$ (b) twins in $\mathrm{NdBa}_{2} \mathrm{Cu}_{3} \mathrm{O}_{7}$ and (c) twins in $\mathrm{Lu}_{0.75} \mathrm{Y}_{0.25} \mathrm{Ba}_{2} \mathrm{Cu}_{3} \mathrm{O}_{7}$.

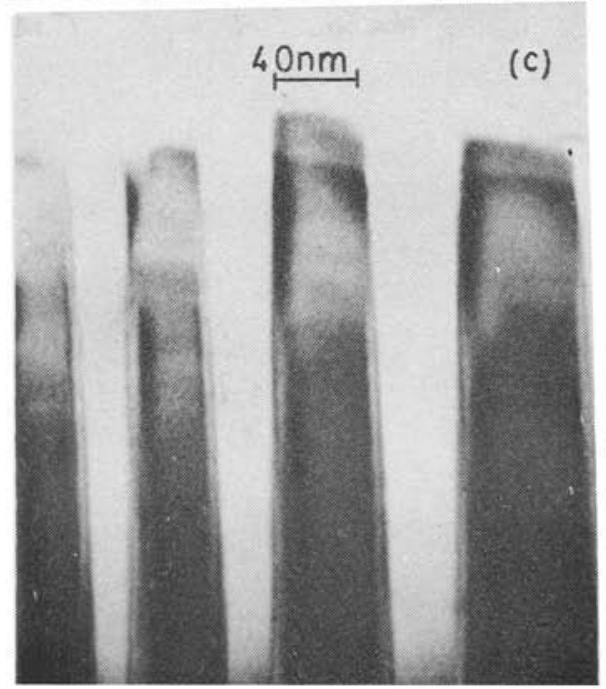




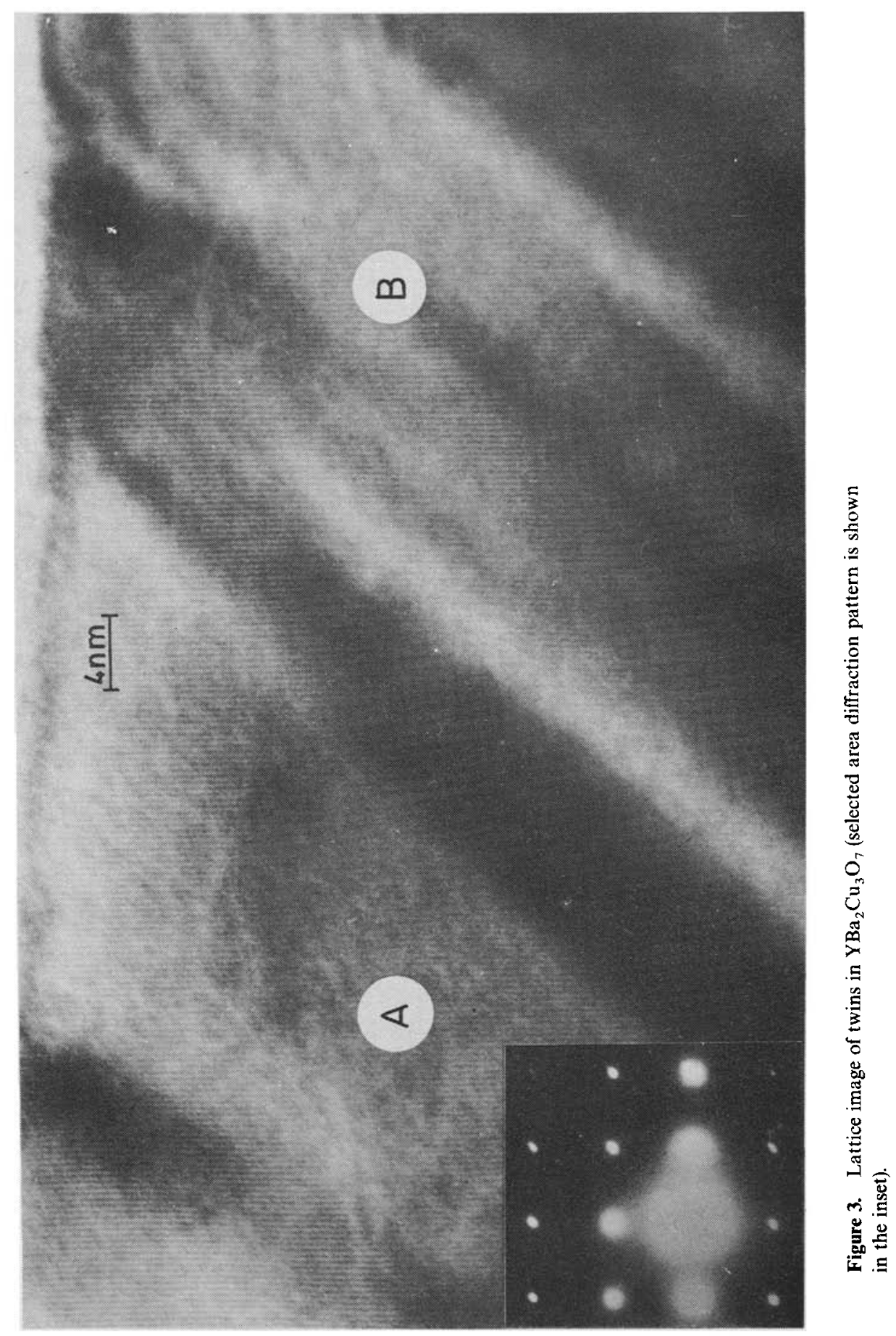



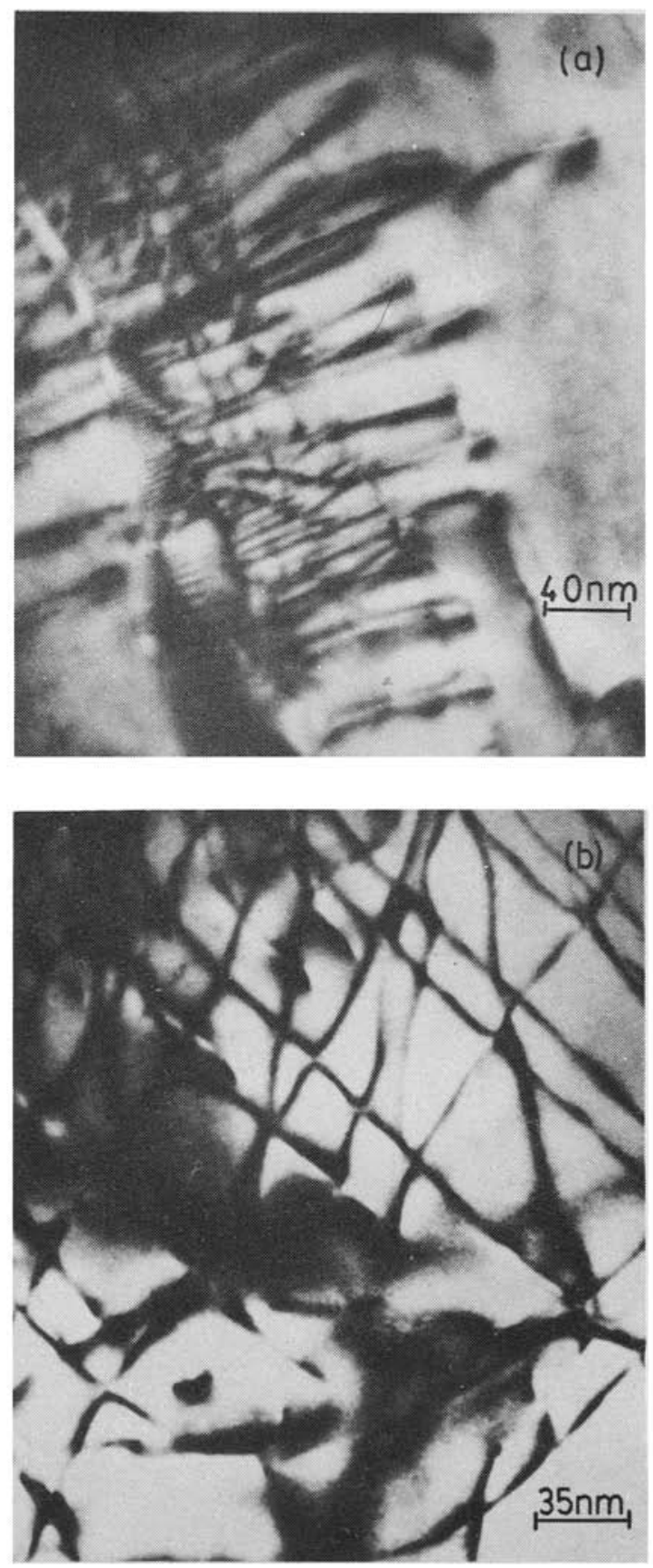

Figure 4. Bright-field images of dislocations in (a) $\mathrm{La}_{1 \cdot 8} \mathrm{Sr}_{0 \cdot 2} \mathrm{CuO}_{4}$ and (b) $\mathrm{La}_{1 \cdot 85} \mathrm{~B}_{0 \cdot 15} \mathrm{CuO}_{4}$ (note samples quenched to $77 \mathrm{~K}$ from room temperature).

the twin population is not altered. We have studied bright-field images of $\mathrm{NdBa}_{2} \mathrm{Cu}_{3} \mathrm{O}_{7}$ and $\mathrm{Lu}_{0.75} \mathrm{Y}_{0.25} \mathrm{Ba}_{2} \mathrm{Cu}_{3} \mathrm{O}_{7}$ both of which are orthorhombic and superconducting $\left(T_{c}\right.$ $\sim 80 \mathrm{~K}$ ). These oxides also show twins (figures $2 \mathrm{~b}$ and $2 \mathrm{c}$ ). The only samples of the 

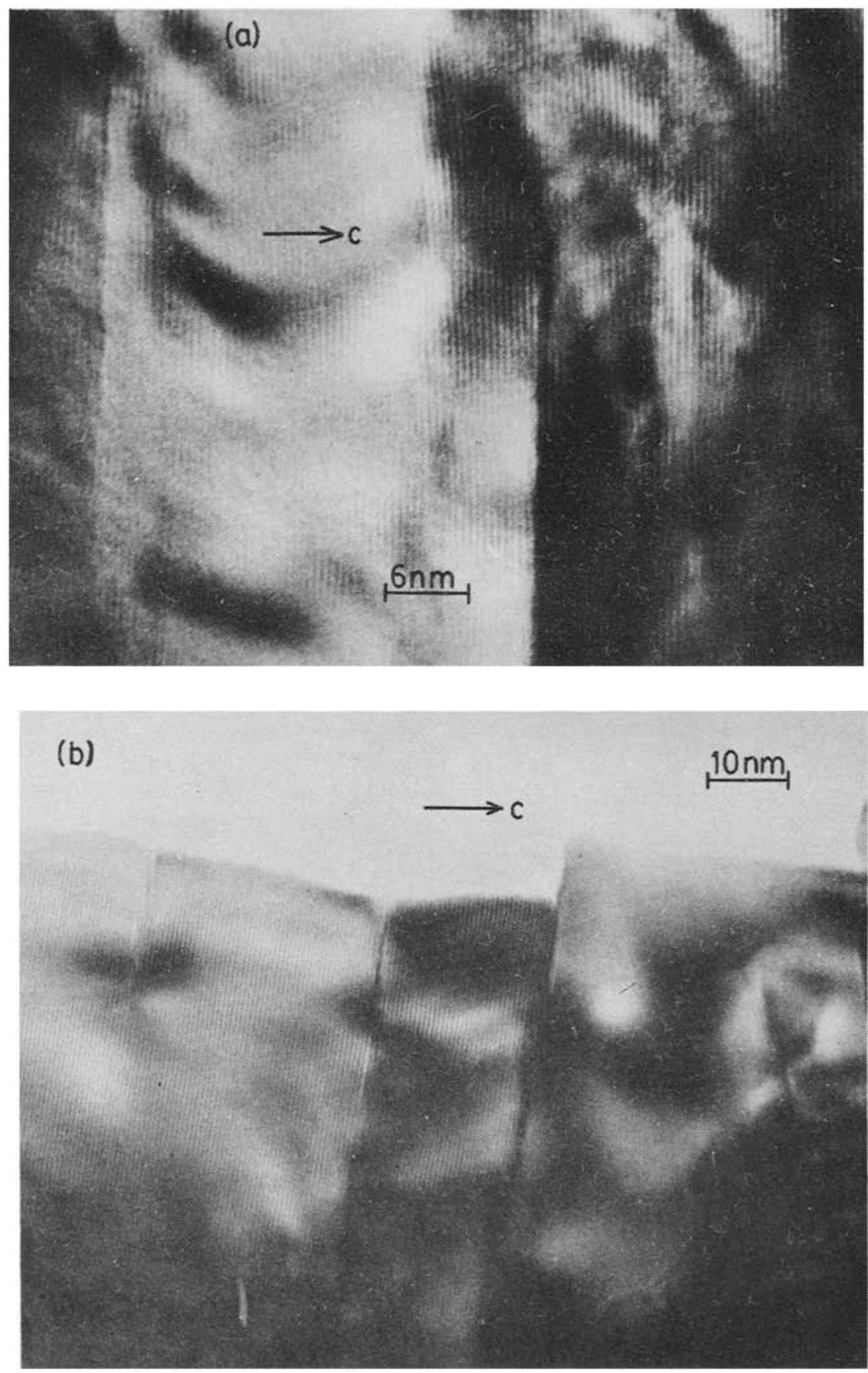

Figure 5. Lattice image of fine domains along c-axis in (a) $\mathrm{La}_{1} \mathrm{Sr}_{0 \cdot 2} \mathrm{CuO}_{4}$ and (b) $\mathrm{La}_{185} \mathrm{Ba}_{015} \mathrm{CuO}_{4}$.

123 oxides without twins are the ones with high oxygen-deficiency (e.g. $\mathrm{YBa}_{2} \mathrm{Cu}_{3} \mathrm{O}_{6}$ ) and the structure is tetragonal.

The twins in $\mathrm{YBa}_{2} \mathrm{Cu}_{3} \mathrm{O}_{7}$ show interesting changes in contrast across the twin domains. Thus within the $\sim 200 \AA$ domains, we often see darker bands of $\sim 90 \AA$ 
width. It was of interest to find out whether this was due to a change in structure and/or stoichiometry of the sample across the twin domains or due to dynamical effects in the microscope. It was also of interest to examine any structural change across the twin boundary. For this purpose, we have studied the high-resolution images of the twin domains of the 123 oxides. In figure 3, we show a typical HREM image of the twin boundary of $\mathrm{YBa}_{2} \mathrm{Cu}_{3} \mathrm{O}_{7}$. It is seen that the lattice fringes run across the boundary continuousiy without any change in contrast, except for a small tilt at the twin interface. There is a subtle change in the lattice fringe spacings from one twin domain to another (twin domain A and B in figure 3), indicating switching of the $a$ and the $b$-axes across the boundary. Since most of the crystals studied were wedge-shaped, dynamical diffraction conditions possibly play an important role in the contrast observed across the twin boundary.

We have examined the possible occurrence of twins in the $\mathrm{La}_{2-x} \mathrm{Sr}_{x}\left(\mathrm{Ba}_{x}\right) \mathrm{CuO}_{4}$ system as well as in $\mathrm{La}_{2} \mathrm{CuO}_{4} \cdot \mathrm{La}_{2-x} \mathrm{Sr}_{x}\left(\mathrm{Ba}_{x}\right) \mathrm{CuO}_{4}$ is tetragonal at room temperature and becomes orthorhombic on cooling to $180 \mathrm{~K}$ (Day et al 1987). Samples of $\mathrm{La}_{1.8} \mathrm{Sr}_{0.2} \mathrm{CuO}_{4}$ and $\mathrm{La}_{1.85} \mathrm{Ba}_{0.15} \mathrm{CuO}_{4}$ show no evidence of twins in the bright-field images at room temperature. On slowly cooling the samples to liquid-nitrogen temperature in the microscope stage no twins developed although the structure becomes orthorhombic. Whether twins will occur at liquid helium temperatures is not clear. Samples of these oxides quenched to liquid nitrogen temperature from room temperature (or higher temperature) showed evidence for high dislocation density (figure $4 a, b$ ), but showed no twins.

$\mathrm{La}_{2} \mathrm{CuO}_{4}$ is orthorhombic at room temperature, but it does not show twins in the bright-field images. According to the empirical rule of Pande et al we should see twins of $\sim 1500 \AA$ width. We see extensive domain patterns along the $c$-axis in the $\mathrm{La}_{2-x} \mathrm{Sr}_{x}\left(\mathrm{Ba}_{x}\right) \mathrm{CuO}_{4}$ system (figure $5 \mathrm{a}, \mathrm{b}$ ) as well as in $\mathrm{La}_{2} \mathrm{CuO}_{4}$. These features may arise from faults in the stacking of $\mathrm{Cu}-\mathrm{O}$ layers along the $c$-axis.

The absence of twins in the oxides of $\mathrm{K}_{2} \mathrm{NiF}_{4}$ structure such as $\mathrm{La}_{2} \mathrm{CuO}_{4}$ and $\mathrm{La}_{2-x} \mathrm{Sr}_{x}\left(\mathrm{Ba}_{x}\right) \mathrm{CuO}_{4}$ is interesting. It seems that the orthorhombic structure is not sufficient for observing twins. It is to be noted that orthorhombic structure of the oxides of $\mathrm{K}_{2} \mathrm{NiF}_{4}$ structure is related to the monoclinic distortion of the tetragonal structure. In 123 oxides such as $\mathrm{YBa}_{2} \mathrm{Cu}_{3} \mathrm{O}_{7}$, however, the orthorhombic structure is determined by the presence of $\mathrm{Cu}-\mathrm{O}$ chains along the $b$-axis. It is this feature which may play an important role in the formation of twins in 123 oxides.

\section{Acknowledgement}

The author thanks Prof. C N R Rao, F.R.S., for suggesting the problems and guidance.

\section{References}

Day P, Resseninsky M, Prassides K, David W I F, Moze O and Soper A 1987 J. Phys. C20 L429

Nelson D L, Whittingham M S and George T F 1987 Chemistry of high temperature superconductors, ACS Symposium Series p. 351

Pande C S, Singh A K, Toth L, Gubser G U and Wolf S 1987 Phys. Rev. B36 105669

Rao C N R 1987 Proc. Adriatico Conf. on high temperature superconductors, (Int. J. Mod. Phys. B1 721)

Rao C N R 1988a J. Solid State Chem. 73

Rab C N R 1988b Chemistry of oxide superconductors (Oxford: Blackwell)

Rao C N R, Ganapathi L and Mohan Ram R A 1988 Mater. Res. Bull. 23

Raveau B C, Michel C and Hervieu M 1987 ACS symposium series 351, chapter 13

Subbanna G N, Ganguly P and Rao C N R 1987 Mod. Phys. Lett. B1 155 